\title{
Topotecan/Paclitaxel/Bevacizumab Regimen
}

National Cancer Institute

\section{Source}

National Cancer Institute. Topotecan/Paclitaxel/Bevacizumab Regimen. NCI Thesaurus.

Code C136242.

A chemoimmunotherapy regimen consisting of topotecan, paclitaxel and bevacizumab that is used for the treatment of cervical cancer. 